C) Copyright 2018: Editum. Servicio de Publicaciones de la Universidad de Murcia. Murcia (Spain) ISSN print edition: 0212-9728. ISSN on line edition (http://revistas.um.es/analesps): 1695-2294. On line edition License Creative Commons 4.0: BY-NC-ND

\title{
Examination of the relationship between phone usage and smartphone addiction based on certain variables
}

\author{
Ahmet Arnavut ${ }^{1}$, Cahit Nuri ${ }^{1}$, and Cemaliye Direktör ${ }^{2 *}$ \\ 1 Ataturk. Faculty of Education, Near East University, Nicosia (Cyprus). \\ 2 Department of Psychology, European University of Lefke, Lefke (Cyprus).
}

Título: Análisis de la relación entre el uso del teléfono y la adicción a teléfonos inteligentes basada en ciertas variables

Resumen: Objetivo: El objetivo del estudio es investigar la relación entre el uso de la tecnología y la adicción a teléfonos inteligentes de acuerdo con ciertas variables.

Método: En este estudio, que se realizó con el propósito de determinar las opiniones de los profesores en prácticas, se empleó un modelo de escaneo. La muestra del estudio consta de 714 maestros en prácticas que estudiaron en la Facultad de Educación de Atatürk de la Universidad del Cercano Oriente, que fueron seleccionados en base a un método de muestreo aleatorio. En el estudio, se utilizó un formulario de información demográfica preparado por los investigadores para obtener los datos requeridos. Se solicitó voluntariamente a los maestros en prácticas que participaron en el es tudio que proporcionaran información sobre sus características demográficas, como edad y sexo, período de uso de redes sociales, hábitos de uso diario de teléfonos inteligentes, tiempo promedio diario en redes sociales, tiempo promedio de uso dispositivos tecnológicos y sus razones para usar teléfonos inteligentes. Se utilizaron la forma abreviada de la Escala de Adicción al Teléfono Inteligente adaptada al idioma turco por Noyan, Darcin, Nurmedov, Yilmaz y Dilbaz, (2015) y la Escala de Opinión para el uso de Dispositivos Tecnológicos desarrollada por Arnavut y Bicen (2013).

Halla goos: El análisis de regresión múltiple realizado mostró que el papel de la tecnología en la vida, la comunicación y el uso de las redes sociales fueron un importante predictor de la adicción a los teléfonos inteligentes $(F(3.709)=282.065, p<.001)$. De acuerdo con los resultados obtenidos, se observó que la varianza total explicaba $54 \%\left(R=.74, R^{2}=.54, p<.001\right)$ Se observó una diferencia significativa en la dimensión de comunicación según la variable de edad de la investigación $(p=.02)$, mientras que no se encontraron diferencias significativas entre la adicción a los teléfonos inteligentes, el uso de las redes sociales y el rol de la tecnología en la vida $(p<$ 05). El análisis de prueba de Tukey mostró que la puntuación de comunicación aumentó con la edad.

Conclusión: De acuerdo con las conclusiones obtenidas, se descubrió que los hombres usan predominantemente teléfonos inteligentes con fines de comunicación. No se encontraron diferencias significativas en términos de adicción a teléfonos inteligentes. Se encontró una relación alta y significativa en una dirección positiva entre la adicción a los teléfonos inteligentes y el uso de las redes sociales. Además, se encontró una relación media y significativa de manera positiva entre la adicción a los teléfonos inteligentes y el papel de la tecnología en la vida.

Palabras clave: tecnología, adicción, uso de tecnología, adicción a los teléfonos inteligentes, estudiante universitario.

\section{Introduction}

Smartphones, which are the most preferred and frequently used communication tools in modern society, have become indispensable parts of daily life, both in North Cyprus and around the world. The excessive use of smartphones by individuals of all ages, but particularly young people, has led to the younger generation becoming addicted to technology.

* Correspondence address [Dirección para correspondencia]:

Cemaliye Direktör. Department of Psychology, European University of Lefke, Lefke, Cyprus, Mersin 10 (Turkey). E-mail: cdirektor@eul.edu.tr
Abstract: Purpose: The purpose of the study is to investigate the relationship between technology usage and Smartphone addiction according to certain variables.

Method: In this study, which was conducted with the purpose of determining the opinions of preservice teachers, a scanning model was employed. The sample of the study consists of 714 preservice teachers who studied at the Atatürk Education Faculty of Near East University, who were selected based on a random sampling method. In the study, a demographic information form prepared by the researchers was used in order to obtain the required data. The preservice teachers who participated in the study voluntarily were asked to provide information on their demographic features such as age and gender, period of using social networking sites, daily usage habits of smartphones, daily average time spent on social networking sites, average time spent using technological devices and their reasons for using smartphones. The Smartphone Addiction Scale Short Form adapted to the Turkish language by Noyan, Darcin, Nurmedov, Yllmaz and Dilbaz, (2015) and the Opinion Scale for Technological Device Usage developed by Arnavut and Bicen, (2013) were both used.

Findings: The conducted multiple regression analysis showed that the role of technology in life, communication and the usage of social media were significant predictor of smartphone addiction $(F(3.709)=282.065, p<$ $.001)$. According to the obtained results, it was seen that the total variance explained $54 \%\left(R=.74, R^{2}=.54, p<.001\right)$. A significant difference was observed in the communication dimension according to the age variable of the research $(p=.02)$, whereas no significant difference was found between smartphone addiction, social media usage and the role of technology in life $(p<.05)$. Tukey test analysis showed that the communication score increased with age.

Conclusion: According to the obtained conclusions, it was found out that males predominantly use smartphones for communication purposes. No significant difference was found in terms of smartphone addiction. A high and significant relationship was found in a positive direction between smartphone addiction and social media usage. Additionally, a medium and significant relationship in a positive direction was found between smartphone addiction and the role of technology in life.

Keywords: Technology, Addiction, Technology usage, Smartphone addiction, University student.
One of the most significant side effects, especially in terms of psychology, is smartphone addiction (Aktas \& Yilmaz, 2017). People can access any information they want rapidly due to the facilities and opportunities provided by technology and the Internet. It is noticeable that people of every age, particularly adolescents, are unable to function without their phones in any environment and tend to express themselves through the virtual medium in their hands instead of contacting others in the real world. Young people prefer to use the Internet for entertainment, relaxing and social interaction as well as to avoid stress, escaping from reality and to achieve a sense of freedom. These purposes that are not de- 
velopmental and can cause harm when used excessively can become problematic over time (Kalkan \& Kaygusuz, 2013; Dirik, 2016). Under today's conditions, visible changes have occurred in people's habits, including their spending, shopping, usage of mobile phones, computers and other technological devices and many other issues. Today, addiction is no longer a unidimensional concept and it is very difficult to define (Dirik, 2016). Addiction is usually caused by the interaction between many factors including biological or genetic inclination, psychological structure, social environment and the nature of the activity (Griffiths, 2003). According to Lee (2006), modern addiction is not only related to drugs or narcotics; it can also refer to over indulgence in gambling, Internet, games, and even smartphones, which fall into the category of behavioural addiction (Kwon, Kim, Cho \& Yang, 2013).

The fact that smartphone users are abundant is defined as irresistible and repeated behaviour, motive control disorder, and having difficulty in resisting an attitude which is harmful to oneself and others according to DSM-IV-TR (2005). Habits are activities which enrich people's lives and make daily life easier. However, if such habits are uncontrollable, leading to the failure to solve problems or threats in social, psychological and cognitive terms, it can be said that they are becoming an addiction. According to data from the Turkish Statistics Institute (2016), the ratio of possession of desktop/movable computers increased from $10.9 \%$ in 2004 to $67.7 \%$ in 2014 , whereas the ratio of possessing mobile phones / smartphones increased by almost 100\% from $53.7 \%$ in 2004 to $96.2 \%$ in 2014. Global sales of smartphones reached 305 million in 2010, and is predicted to increase to three billion in 2018. This data implies that today, computers have been replaced by smartphones (IDC, 2017; TUIK, 2017). Technological developments have created stronger, more user friendly, more portable and personal, smaller devices. The best example of this development is smartphones, which combine mobile phones with palmtop computer technologies (Chen, Chen \& Yen, 2011). Smartphones have been one of the most rapidly growing technologies in the mobile phone market since 1996 (Choudrie, Pheeraphuttharangkoon, Zamani \& Giaglis, 2014), and they act as a personal assistant which combines several features such as voice search, GPS navigation systems, camera and video camera, music and movie player, and Internet access for web and e-mail in cellular phones. Sharing information, sending and receiving e-mails, chatting, opening and organizing documents, reviewing and shopping, making payments for products and several other activities which can be achieved with normal computers can now also be performed using smartphones (Alfawareh \& Jusoh, 2014).

A review of the literature reveals that there aretechnological addictions such as television addiction (Kubey \& Csikszentmihalyi, 2002), online pornography addiction (Owens, Behun, Manning \& Reid, 2012), online shopping addiction (Dittmar, Long \& Bond, 2007) and online sex addiction
(Griffiths, 2001) in addition to Internet, social media, digital games and smartphone addictions. However, in the present study, the concept of technological addictions is limited to Internet addiction. In this paper, the relationship between the technological addictions and smartphone addiction of university students and the impact of demographic features has been examined. No study in the literature has been found which has examined the effect of technological addictions on smart phone addiction. Therefore, it is believed that this study reveals important conclusions in regard to the impact of university students' technology addiction on smartphone addiction.

\section{Method}

\section{Model of The Study}

In this study, which was conducted with the purpose of determining the opinions of teacher candidates on technology usage and smartphone usage, a scanning model was employed.

\section{Study Group}

The sample of the study consisted of 714 pre-service teachers studying at the Near East University Atatürk Education Faculty in the 2016-2017 academic year, chosen with a random sampling model. A total of $412(57.7 \%)$ males and $302(42.3 \%)$ females participated in the study.

\section{Data Collection Tools}

Demographic information form: In order to obtain the data needed in the research, a demographic information form that was developed by the researchers was used. The preservice teachers who participated in the study voluntarily were asked about their demographic features, such as age and gender, social networking sites usage habits, daily usage times of smartphones, daily average time spent on social networking sites, average time spent using technological devices and their reasons for using smartphones.

Smart phone addiction scale short form: ATBÖ-KF was developed by Kwon et al. (2013) in order to measure the smart phone addiction risk in adolescents and was adapted to Turkish by Noyan, Darçin, Nurmedov, Yilmaz and Dilbaz (2015). It consists of 10 items and evaluates using a six-point Likert-type scale. Higher scores in the test indicate that the risk of addiction is greater. The Cronbach's alpha coefficient of the short form is 0.87 .

Opinion scale for technological device usage: The opinion scale for technological device usage developed by Arnavut and Bicen (2013) uses a five-point Likert-type scale consisting of five categories, namely "strongly agree, agree, neither agree nor disagree, disagree, strongly disagree". Factor analysis revealed five dimensions. The scale was structured in a fivefactor fashion and the contents and structures of the factors 
were organized as "technological device opinions" (24), "social media" (12 items), "the roleof technology in life" (8 items), "educative usage" (9 items), and "communication" (7 items). In order to examine the discriminative features of the items in the scale, total correlations were calculated for 60 items which appeared between .530 and .915 .

\section{Findings}

Based on the test results, the differences between the preservice teachers in terms of "smartphone addiction", "social media usage", "technology addiction" and "communication usage" according to the gender variable were examined. According to the obtained findings, a significant difference was found between smartphone addiction $(p<.01)$ and the communication usage $(\phi<.01)$ of pre-service teachers according to gender, whereas no significant difference was found between social media usage and technology addiction $(p>.05)$. The smartphone addiction score for females $(\bar{X}=28.81)$ was found to be higher compared to males $(\bar{X}=28.77)$. Using technology for communication scores were found to be higher in males $(\bar{X}=17.25)$ compared to females $(\bar{X}=16.32)$.

Table 1. T-test results of smart phone addiction according to gender.

\begin{tabular}{|c|c|c|c|c|c|c|}
\hline & & $N$ & $\bar{X}$ & $S S$ & $d f$ & $T$ \\
\hline \multirow[t]{2}{*}{ Smart phone addiction } & Female & 302 & 28.81 & 10.52 & 712 & .964 \\
\hline & Male & 412 & 28.77 & 11.89 & 712 & \\
\hline \multirow[t]{2}{*}{ Social media } & Female & 302 & 27.94 & 8.39 & 712 & .762 \\
\hline & Male & 412 & 27.75 & 8.35 & 712 & \\
\hline \multirow[t]{2}{*}{ Technology addiction } & Female & 302 & 27.93 & 5.72 & 712 & \\
\hline & Male & 412 & 27.93 & 6.15 & 712 & .991 \\
\hline \multirow[t]{2}{*}{ Communication } & Female & 302 & 16.32 & 4.87 & 712 & \\
\hline & Male & 412 & 17.25 & 5.87 & 712 & $.026^{*}$ \\
\hline
\end{tabular}

${ }^{*} p<.05 ;{ }^{* *} p<.01 ; * * * p<.001$

Table 2. Anova results of smartphone addiction according to age.

\begin{tabular}{|c|c|c|c|c|c|}
\hline & & Sum of squares & $D f$ & Mean squares & $F$ \\
\hline \multirow[t]{2}{*}{ Smart phone addiction } & Inter-group & 154.49 & 2 & 77.25 & 0.601 \\
\hline & Intra-group & 91395.72 & 711 & 128.55 & \\
\hline \multirow[t]{2}{*}{ Social media } & Inter-group & 130.23 & 2 & 65.12 & 0.931 \\
\hline & Intra-group & 49733.59 & 711 & 69.95 & \\
\hline \multirow[t]{2}{*}{ Technology addiction } & Inter-group & 22.58 & 2 & 11.29 & 0.316 \\
\hline & Intra-group & 25411.32 & 711 & 35.74 & \\
\hline \multirow[t]{2}{*}{ Communication } & Inter-group & 220.667 & 2 & 110.33 & $3.686^{*}$ \\
\hline & Intra-group & 21260.18 & 711 & 29.93 & \\
\hline
\end{tabular}

${ }^{*} p<.05 ;{ }^{* *} p<.01 ; * * * p<.001$

The survey results of pre-service teachers were also examined according to the age variable. As per the obtained results, a significant difference was only found in the using technology for communication purposes dimension among the three different age groups of the participants $(p<0.05)$. Accordingly, the mean values the participants aged $18-25$ in regard to using technology for communication purposes $(\bar{X})$ was found to be $16.66,17.32(\bar{X})$ for $26-29$ years of age participants, and $19.22(\bar{X})$ for participants aged 30 years and above. Differences between the groups were examined with Tukey and it was found out that the difference was between the 18-25 age interval and the group above 30 years of age ( $p$ $<.05)$. The finding obtained from these results is that there is no significant difference between the answers given by participants in terms of the smartphone addiction, social media usage and technology addiction dimensions according to the age groups. It was determined that a significant difference existed between the social media usage, technology addiction and smart phone addiction scores according to the age variable $(p>.05)$.
Table 3. The relationship between smartphone addiction and technology usage variables.

\begin{tabular}{llll}
\hline & 1 & 2 & 3 \\
\hline Smart phone addiction & - & & \\
Social media usage & $.603^{* * *}$ & - & \\
Technology addiction & $.422^{* * *}$ & $.386^{* * *}$ & - \\
Communication & $.680^{* * *}$ & $.581^{* * *}$ & $.373^{* * *}$ \\
${ }^{*} p<.05 ;{ }^{* *} p<.01 ;{ }^{* * *} p<.001$ & & &
\end{tabular}

Pearson correlation analysis was conducted in order to examine the relationship between the variables. When the values are examined, it is found that that there is a high level, significant and positive relationship between smartphone addiction and social media usage $(p<.001)$; a medium level, significant and positive relationship between smartphone addiction and technology addiction $(p<.001)$; and a high level, significant and positive relationship between smartphone addiction and communication $(\phi<.001)$. 
Table 4. Multiple regression analysis in regard to the predictive variables of smartphone addiction.

\begin{tabular}{lccccc}
\hline \multicolumn{1}{c}{ Constant } & $\mathrm{B}$ & $\mathrm{SS}$ & $\beta$ & $t$ & $p$ \\
\hline Social media usage & -5.368 & 1.466 & - & -3.662 & .000 \\
Technology addiction & .376 & .043 & .277 & 8.674 & .000 \\
Communication & .267 & .053 & .141 & 5.030 & .000 \\
\hline
\end{tabular}

${ }^{*} p<.05 ;{ }^{* *} p<.01 ; * * * p<.001$

When the analysis results are examined, it is seen that social media usage, technology addiction and communication sub-dimensions are predictors of smartphone addiction, $R=0.738, R^{2}=0.544$, Adapted $R^{2}=0.542$, $F(3.710)=282.411, p<0.001$. It can be stated that $54 \%$ of the variance related to smartphone addiction is explained with social media usage, technology addiction and communication. An examination of the variables that explain the mentioned variance shows that social media usage, technology addiction and communication are predictors of smartphone addiction.

\section{Discussion}

According to the findings obtained in the study, it is revealed that there are differences in terms of smartphone addiction based on the genders of the pre-service teachers. An examination of the literature reveals that smartphone addiction is more prevalent among males than females (Noyan et al, 2015; Arnavut \& Bicen, 2013). However, in this study, females received higher smartphone addiction scores than males. Cultural differences are remarkable in psychological evaluations. It is believed that the research group had a different cultural structure compared to previous studies. Several studies have indicated that there is a relationship between smartphone addiction and negative feelings and loneliness (Dirik, 2016; Aktas \& Y1lmaz, 2017). It is known that females experienced more challenges when living in a different country than their home country. In the present study, the research group consists of university students. In this direction, it is believed that female pre-service teachers suffer from higher risks of smart phone addiction in the process of adapting to the new environment. Another important find-

\section{References}

Aktaş, H., \& Yılmaz, N. (2016). Smartphone addiction in terms of the elements of loneliness and shyness of university youth. International Journal of Social Sciences and Education Research, 3(1), 85-100. DOI: 10.24289 /ijsser.283590.

Alfawareh, H. M., \& Jusoh, S. (2014). Smartphones usage among university students: najran university case. International Journal of Academic Research, 6(2). doi:10.7813/2075-4124.2014/6-2/B.48.

Arnavut, A. (2013). Determination of Opinions of Pre-Service teachers in Turkish Republic of Northern Cyprus as regards Usage of Technological Devices (Master's Thesis). Near East University, TRNC.

Chen, K., Chen, J. V., \& Yen, D. C. (2011). Dimensions of self-efficacy in the study of smart phone acceptance. Computer Standards \& Interfaces, 33(4), 422-431. doi:10.1016/j.csi.2011.01.003 ing is that using technology for communication purposes is higher among male preservice teachers than females. Studies on technology have stated that males are more inclined to technology addictions (Noyan et al, 2015; Arnavut \& Bicen, 2013). In addition, the fact that the present study indicates that technology is more widely used by males for communication purposes coincides with the findings in the literature. Another finding related to the use of technology for communication purposes was revealed in the age variable. It was found that individuals in the older age groups use technology more for communication purposes. A high level and positive significant relationship was found between smartphone addiction and social media usage, whereas a medium level and positive significant relationship was identified with the role of technology in life. There search results showed that technology addiction, social media usage and usage of technology for communication purposes variables were predictors of smartphone addiction. It is known that addictions are related to each other. In recent years in particular, the relationship between Internet addiction and smart phone addiction, which are behavioural addictions, has emerged, which is an expected situation (Alfawareh \& Jusoh, 2014; Kubey \& Csikszentmihalyi, 2002; Owens, Behun, Manning \& Reid, 2012). In regard to the relationship between smartphone addiction and technological developments, smartphone addiction explains $54 \%$ of the total variance.

The research group covers only pre-service teachers. It is recommended that in future studies, comparisons should be made with other professional groups. Online courses are now developed at education faculties. Consequently, studies that include humanities and engineering faculties will enrich the field. Another important point is that the study participants are studying outside of their native country. There are some studies in the literature that have shown the relationship between loneliness and smartphone addiction. Another feature of the research group is that they study at a private university. It should be considered that access to technology and smartphones can increase the addiction scores. It is recommended that further studies should include research groups with different cultural features and different age intervals.

Choudrie, J., Pheeraphuttharangkoon, S., Zamani, E. \& Giaglis G. (2014). Investigating the adoption and use of smartphones in the UK: a silversurfers perspective. UH Business School Working Paper, University of Hertfordshire. http://hdl.handle.net/2299/13507.

Dirik, K. (2016). Examination of the relations between smart phone addiction and self-confidence in adolescents in terms of several variables (Master's Thesis). Istanbul Gelisim University, Graduate School of health Sciences, Istanbul.

Dittmar, H., Long, K., \& Bond, R. (2007). When a better self is only a button click away: Associations between materialistic values, emotional and identity-related buying motives, and compulsive buying tendency online. Journal of social and clinical psychology, 26(3), 334-361. doi:10.1521/jscp.2007.26.3.334 
Griffiths, M. (2001). Sex on the Internet: Observations and implications for Internet sex addiction. Journal of sex research, 38(4), 333-342. DOI: $10.1080 / 00224490109552104$

Griffiths, M. (2003). Internet gambling: Issues, concerns, and recommendations. CyberPsychology \& $\quad$ Behavior, 6(6), 557-568. doi:10.1089/109493103322725333

IDC, (2017). International Data Corporation Worldwide Mobile Phone 2014-2018 Forecast and Analysis. Accessed on 7th of October, 2017.

TUIK, (2017). Turkish Statistics Institution Household Informatics Technologies Usage Research, 2004-2014. Accessed on 7th of October, 2017.

Kalkan M, \& Kaygusuz C. (ed.) (2013). Internet addiction: Problems and Solutions. Ankara: An1 Publications.

Kubey, R., \& Csikszentmihalyi, M. (2002). Television addiction is no mere metaphor. Scientific American, 286(2), 74-80. Accessed on 7th of October 2017. http://www.jstor.org/stable/26059563
Kwon, M., Kim, D. J., Cho, H., \& Yang, S. (2013). The smartphone addiction scale: development and validation of a short version for adolescents. PloS one, 8 (12), e83558. doi:10.1371/journal.pone.0083558

Noyan, C. O., Darçın, A. E., Nurmedov, S., Yılmaz, O., \& Dilbaz, N. (2015). Validity and reliability of the Turkish version of the Smartphone Addiction Scale-Short Version among university students. Anatolian Journal of Psychiatry, 16, 73-81. doi:10.5455/apd.176101

Owens, E. W., Behun, R. J., Manning, J. C., \& Reid, R. C. (2012). The impact of Internet pornography on adolescents: A review of the research. Sexual Addiction \& Compulsivity, 19(1-2), 99-122. doi:10.1080/10720162.2012.660431

(Article received: 12-02-2018; revised: 26-03-2018; accepted: 09-04-2018) 